\title{
The role of attention in the perception of the Ponzo illusion
}

\author{
JACK G. THOMPSON \\ Centre College of Kentucky, Danville, Kentucky 40422 \\ and \\ H. R. SCHIFFMAN \\ Rutgers University, New Brunswick, New Jersey 08903
}

\begin{abstract}
An experiment was performed to test whether the Ponzo illusion is primarily determined by attentional factors. "Attention" was manipulated by varying the similarity of the figural components, that is, the color of the horizontal test lines. Minimizing the similarity between the test lines and the enclosing contours caused a decrement in magnitude but did not eliminate the illusion. Based on the findings reported herein, it appears reasonable to assume that attention plays only a minor role in the actuation of the illusion.
\end{abstract}

Pressey (1971) has argued that the Ponzo illusion results from the observer's inability to focus his attention only on the two horizontal test lines of the figure (Figure 1A). Although the observer's task is to judge the length of the two test lines, due to proximity, segments of the adjacent contours also fall directly within the field of attention (see Figure 1B) and influence the observer's judgment. According to this view, the two lines that are to be compared are actually judged in different contexts. Specifically, the upper line is judged relative to the area bounded by the adjacent contours and therefore appears elongated relative to the "unbounded" lower line.

Although Pressey's (1971) assertion that only the upper test line is perceived nonveridically appears to be invalid (e.g., Fisher, 1968; Quina \& Pollack, 1972), his concept that the Ponzo illusion is produced by attentional factors is intuitively appealing. The major difficulty in testing this notion is the manipulation of attention. Pressey, Butchard, and Scrivner (1971), for example, manipulated "attention" by varying the angle of the enclosing contours of the Ponzo figure. Although their underlying assumption may be valid (i.e., the segments of the figure that observers attend to may vary as a function of the angle of the enclosing contours), it should be stressed that this manipulation alters both the contextual relationships and the apparent depth inherent in the figure (see Fisher, 1973). Thus, any changes in the magnitude of the illusion produced by this manipulation may be attributed to "attention," or "nonattentional" factors, or their combined influence.

This research was conducted at Rutgers University with the support of Grant 07-2109 from the Rutgers University Research Council and the Charles and Joanna Busch Memorial Fund to the second author.

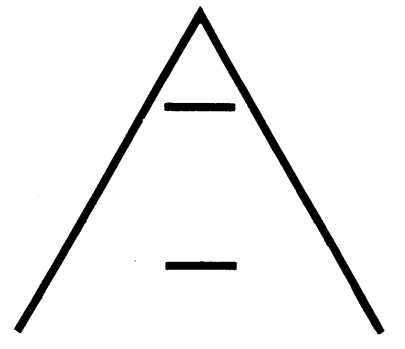

A

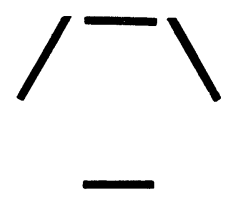

B
Figure 1. (1) The Ponzo illusion and (B) the segments of the Ponzo figure that fall directly within the field of attention according to Pressey (1971).

Accordingly, the present study was performed to reexamine the role of attention in the actuation of the Ponzo illusion by varying the similarity of the figural components. Specifically, "attention" was manipulated by varying the color of the two horizontal test lines. Based on Coren and Girgus' (1972) findings with the Mueller-Lyer illusion, it was hypothesized that the color of the test lines and the enclosing contours of the Ponzo figure should directly influence the manner in which the observer attends to the figure. That is, it should be more difficult for the observer to ignore the enclosing contours when all the segments of the figure are the same color than when both test lines are one color and the enclosing contours are a different color. Additionally, Pressey's (1971) model of attention was tested by varying the color of a single test line. According to his explanation, the magnitude of the illusion should vary with the location of the "oddcolored" line. Locating the odd-colored line near the divergent end of the figure should have no effect on the illusion; locating this line near the vertex should 
cause a decrement, since it should be easier for the observer to ignore the enclosing contours than when the upper test line and the contours are the same color.

\section{METHOD}

\section{Subjects}

The subjects were 40 male volunteers from an introductory course in psychology at Rutgers University and were naive as to the intent of the experiment. All subjects had uncorrected normal vision and tested $20 / 30$ or better in binocular recognition acuity.

\section{Stimuli}

Four series of Ponzo figures were used. The enclosing contours of all figures were glossy green (Letraline 1253) graph tape. In Series 1 both horizontal lines were green. In Series 2 the line closest to the vertex was green and the line closest to the divergent end of the figure was red. In Series 3 the line closest to the vertex was red and the line closest to the divergent end was green. In Series 4 both horizontal lines were red. In all cases the horizontal line closest to the vertex served as the standard stimulus and was fixed in length at $15 \mathrm{~mm}$. At this viewing distance $(55 \mathrm{~cm})$, this line subtended a visual angle of $1 \mathrm{deg} 34 \mathrm{~min}$. The horizontal lines located near the divergent end of the figure served as comparison lines and varied in length from 11 to $19 \mathrm{~mm}$, in equal steps of $1 \mathrm{~mm}$, producing a total of nine comparison stimuli. Each stimulus was constructed of 1.5-mm-wide graph tape mounted on cards of white poster board. The green figure segments were constructed from glossy green (Letraline 1253) graph tape, and the red figure segments were constructed from glossy red (Letraline 1203) graph tape. For all figure presentations, a small black fixation target was located in the center of the preexposure field. During testing, the midpoint of each stimulus figure was congruent with the location of the fixation target.

\section{Apparatus}

The main testing apparatus was a two-channel tachistoscope (Gerbrands, Model T1C). The tachistoscope was mounted on top of a 71-cm-high table, and the entire apparatus except for the viewing aperture of the tachistoscope was concealed from the subjects. The rated light output of the display field was $104 \mathrm{~lm}$. Room illumination was measured at $79 \mathrm{~cd}^{-2} \mathrm{~m}$.

\section{Design and Procedure}

A between-groups design was employed. Ten subjects were randomly assigned to each of four stimulus series.

The psychophysical random method of limits was employed (see Herrick, 1973). Each subject was presented with eight blocks of nine stimulus presentations per block, for a total of 72 judgments per subject. All nine comparison stimuli were presented in each block in random order. A different randomization order was employed on each block and for each subject.

The procedure was identical for all subjects. The subjects were seated in front of the tachistoscope and allowed to view the fixation field. The subjects were instructed to focus on the fixation target and not to move their eyes when the figures were presented. The fixation instructions were repeated throughout the testing session to minimize anticipatory eye movement responses. Immediately prior to testing, a sample Ponzo figure was presented to familiarize the subjects with the task. The test stimuli were presented for $1 \mathrm{sec}$. The interstimulus interval was $15 \mathrm{sec}$, during which the subjects reported whether the comparison horizontal line appeared "longer than" or "shorter than" the horizontal standard. "Equal" judgments were not allowed, and the subjects were instructed to guess when unsure.

\section{RESULTS AND DISCUSSION}

Mean points of subjective equality (PSEs), constant error (CEs), standard deviations (SDs), and the percentages of illusion for the experimental conditions are shown in Table 1.

An analysis of variance performed on the PSE values resulted in a significant main effect of figure type $[F(3,36)=3.65, p<.05]$. A Newman-Keuls test was performed on the PSE values for the four figure conditions. Only stimulus Series 4 (green contours and red test lines) differed significantly from the other three stimulus series $(p<.05)$.

Clearly, these results indicate that attentional factors play a role in determining the magnitude of the Ponzo illusion. Specifically, minimizing the similarity between the test lines and the enclosing contours (Series 4) resulted in about a $2 \%$ decrease in the magnitude of the illusion. However, the results do not indicate that the Ponzo is exclusively determined by attentional factors. The occurrence of a rather robust illusion in Series 4 suggests that attention may play only a secondary or facilitative role in determining the magnitude of the illusion. Moreover, it is difficult to reconcile Pressey's model with the finding that the magnitude of the illusion was not affected by the location of the oddcolored line in Series 2 and 3.

In general, the results of the present experiment are consistent with earlier reports that both test lines of the Ponzo figure are perceived nonveridically (e.g., Fisher, 1968; Quina \& Pollack, 1972). Although there is little theoretical agreement over what factors produce these distortions in perceived length, it is clear that any comprehensive explanation of the Ponzo illusion should account for this empirical finding.

Table 1

Mean Points of Subjective Equality (PSE), Constant Errors (CE), Standard Deviations (SD), and Percentage of Illusion as a Function of Stimulus Series

\begin{tabular}{clcccc}
\hline Series & Color of Test Lines & PSE $(\mathrm{mm})$ & CE $(\mathrm{mm})$ & SD & $\begin{array}{c}\text { Percentage } \\
\text { Illusion* }\end{array}$ \\
\hline 1 & Both Green & 16.26 & 1.26 & .22 & 8.42 \\
2 & Upper Green, Lower Red & 16.19 & 1.19 & .26 & 7.92 \\
3 & Upper Red, Lower Green & 16.21 & 1.21 & .19 & 8.08 \\
4 & Both Red & 15.92 & .92 & .20 & 6.17 \\
\hline
\end{tabular}

*Percentage illusion $=[(P S E-$ standard stimulus $) /($ standard stimulus $) / \times 100$. 


\section{REFERENCES}

Coren. S.. \& Girgus, J. S. Differentiation and decrement in the Mueller-Lyer illusion. Perception \& Psychophysics, 1972, 12. 466-470.

Fisher, G. H. Gradients of distortion seen in the context of the Ponzo illusion and other contours. Quarterly Journal of Experimental Psychology, 1968, 20, 212-217.

Fisher, G. H. Towards a new explanation for the geometrical illusion: II. Apparent depth or contour proximity? British Journal of Psychology, 1973, 64, 607-621.

Herric K. R. M. Psychophysical methodology: VI. Random method of linits. Perception and Psychophysics. 1973, 13. 548-554.

Pressey, A. W. An extension of assimilation theory to illusions of size, area, and direction. Perception \& Psychophysics, 1971, 9. 172-176.

Pressey, A. W., Butchard, N., \& Schrivner, L. Assimilation theory and the Ponzo illusion: Quantitative predictions. Canadian Journal of Psychology, 1971, 25, 486-497.

Quina, K., \& Pollack, R. H. Effects of test line position and age on the magnitude of the Ponzo illusion. Perception \& Psychophysics, 1972, 12, 253-256.

(Received for publication February 23, 1979.) 